Jurnal Akuakultur Sungai dan Danau Vol. 3 No. 1 Tahun 2018 Hal. 27 - 34

ISSN Print 2503-4766

ISSN Online 2597-8837

\title{
ANALISIS KANDUNGAN MERKURI (HG) DI DALAM TUBUH IKAN \\ PATIN SIAM (Pangasius hypopthalmus) YANG DIBERI PERLAKUAN \\ FITOREMEDIASI DENGAN TAMANAN AZOLLA (Azolla microphilla)
}

\author{
Safratilofa $^{1}$ dan Kaizar $^{2}$ \\ ${ }^{1}$ Program Studi Budidaya Perairan, Fakultas Pertanian Universitas Batanghari \\ ${ }^{2}$ Mahasiswa Program Studi Budidaya Perairan, Fakultas Pertanian Universitas Batanghari \\ Jl. Slamet Riyadi, Broni Jambi. 36122. Telp. +62074160103 \\ ${ }^{1}$ Email korespondensi : osa.safra@yahoo.com
}

\begin{abstract}
In 2014 the Batanghari River has been polluted with severe polluted category entering into class D group by Jambi Provincial Environment Agency 2014 with effluent content of $0.3265 \mathrm{ppm}$. One of the contaminants is mercury (Hg). This is due to increased mining, industrial and agricultural activities along the Batanghari River. Batanghari River is a source of water for Sipin Lake. Sipin Lake has much to do with fish farming in KJA for catfish. The potential of $\mathrm{Hg}$ content in the waters has exceeded the standard quality standard that can thwart the fish farming activities. Therefore, research to find solutions to solve the contamination of mercury (Hg) content in catfish (Pangasionodon hypopthalmus) with technical use of azolla (Azolla microphilla) as phytoremediation to prevent $H g$ from entering fish body. This Research conducted around KJA fish cultivation in the waters of Sipin Lake Jambi. The design of this research is Completely Randomized Design with azolla density level as treatment. The results of analysis and observation showed that the density of azolla gave no significant effect on the content of mercury $(\mathrm{Hg})$ in water and fish meat
\end{abstract}

Keyword: phytoremediation, markuri, sipin lake, Azolla microphilla, Pangasionodon hypopthalmus

\begin{abstract}
Abstrak
Pada tahun 2014 Sungai Batanghari sudah mengalami pencemaran dengan kategori tercemar berat masuk yang termasuk kedalam golongan kelas D oleh Badan Lingkungan Hidup Provinsi Jambi 2014 dengan kandungan effluen sebesar 0,3265 ppm. Salah satu yang menjadi bahan pencemar adalah merkuri $(\mathrm{Hg})$. Hal ini disebabkan karena meningkatnya kegiatan pertambangan, industri dan pertanian disepanjang Sungai Batanghari. Sungai Batanghari merupakan sumber air bagi Danau Sipin. Danau Sipin berhubungan banyak dengan dengan usaha budidaya ikan di KJA untuk jenis peliharaan ikan patin. Potensi kandungan $\mathrm{Hg}$ pada perairan telah melebihi dari standar baku mutu yang dapat menggagalkan kegiatan budidaya ikan. Untuk itu dilakukan penelitian untuk mencari solusi mengatasi pencemaran kandungan merkuri $(\mathrm{Hg})$ pada ikan patin (Pangasionodon hypopthalmus) dengan teknis pemanfaatan azolla (azolla microphilla) sebagai fitoremediasi untuk mencegah $\mathbf{H g}$ masuk kedalam tubuh ikan. Penelitian dilaksanakan disekitar KJA budidaya ikan di perairan danau Sipin Kota Jambi. Rancangan penelitian yang digunakan ini adalah Rancangan Acak Lengkap dengan tingkat kepadatan azolla sebagai perlakuan. Hasil analisis dan pengamatan
\end{abstract}

Diterbitkan oleh Program Studi Budidaya Perairan Fakultas Pertanian Universitas Batanghari Halaman 27 
Jurnal Akuakultur Sungai dan Danau Vol. 3 No. 1 Tahun 2018 Hal. 27 - 34

ISSN Print 2503-4766

ISSN Online 2597-8837

menunjukkan bahwa kepadatan azolla memberikan pengaruh berbeda tidak nyata tehadap kandungan merkuri $(\mathrm{Hg})$ didalam air dan daging ikan.

Kata Kunci : Fitoremediasi, Markuri, danau sipin, azolla, ikan patin

PENDAHULUAN

Danau sipin berfungsi sebagai salah satu sentra budidaya ikan yang sangat berperan penting dalam penyediaan stok ikan konsumsi bagi masyarakat Propinsi Jambi. Perairan danau sipin merupakan salah satu danau air tawar yang sumber airnya berasal dari sungai Batang Hari. Ketersediaan air yang cukup sepanjang tahun menjadikan danau ini sebagai tempat budidaya ikan oleh masyarakat sekitar. Hampir seluruh masyarakat disekitar danau sipin menggantungkan hidupnya kepada danau ini. Kegiatan budidaya ikan dalam karamba jaring apung (KJA) merupakan usaha yang ditekuni sebagai sumber perekonomian masyarakat.

Tercemarnya perairan oleh merkuri cenderung terjadi akibat adanya aktifitas manusia disepanjang aliran sungai terutama pada bagian hulu. Penggunaan pestisida, buangan limbah industry dan kegiatan pertambangan yang menggunakan merkuri merupakan factor utama yang menyebabkan meningkatnya kandungan merkuri di perairan. Badan Lingkungan Hidup (BLH) Propinsi Jambi menetapkan bahwa pada tahun 2013 di sungai Geragai Kabupaten Tanjung Jabung Timur yang merupakan bagian hilir sungai Batang Hari memiliki kandungan merkuri sebesar 0,08 ppm. Selanjutnya pada tahun 2014 terjadi peningkatan konsentrasi $\mathrm{Hg}$ di perairan sungai batanghari dengan kategori tercemar berat atau masuk kedalam golongan kelas D dengan kandungan effluen sebesar 0,3265 ppm (Kompas, 2014). Nilai tersebut sudah melebihi ambang batas kadar merkuri di perairan yang sebesar 0,02 ppm (Peraturan Gubernur no 27 th 2007).

Penurunan kualitas air danau Sipin terjadi akibat adanya aktifitas manusia di sekitar aliran sungai. Salah satunya yaitu adanya penambangan emas tanpa izin (PETI) yang dilakukan pada bagian hulu sungai. Penggunaan merkuri (Hg) pada penambangan emas menjadi penyebab utama tercemarnya air sungai. Di dalam air, merkuri dapat mengalami biotransformasi menjadi senyawa organik metil merkuri atau fenil merkuri akibat proses dekomposisi oleh bakteri. Selanjutnya senyawa organik tersebut akan terserap oleh jasad renik yang selanjutnya akan masuk dalam rantai makanan dan akhirnya akan terjadi akumulasi dan biomagnifikasi dalam tubuh hewan air seperti ikan dan kerang, yang akhirnya dapat masuk ke dalam tubuh manusia yang mengkonsumsinya (Widhiyatna, 2005).

Menurut Mardekawati et al. (2012) salah satu alternatif yang dapat digunakan untuk mengurangi pencemaran merkuri $(\mathrm{Hg})$ adalah dengan menggunana metode fitoremediasi. Lebih lanjut menurut Hidayati (2013), salah satu pendekatan untuk meremediasi lingkungan tercemar logam adalah dengan fitoekstraksi menggunakan tanaman hiperakumulator. Dengan berkembangnya teknologi fitoremediasi maka tumbuhan hiperakumulator logam menjadi sangat penting. Berdasarkan hasil penelitian Mahmud et al. (2012) tumbuhan yang terdeteksi mampu mengakumulasi merkuri terbesar di ekosistem Sungai Tulabolo adalah tumbuhan paku air (Azolla) dengan konsentrasi merkuri terbesar di akar sebesar $4084 \mathrm{ppb}$ dan didaun sebesar $641 \mathrm{ppb}$. Sebagai solusi mengatasi 
Jurnal Akuakultur Sungai dan Danau Vol. 3 No. 1 Tahun 2018 Hal. 27 - 34

pencemaran kandungan merkuri $(\mathrm{Hg})$ pada air dan daging ikan patin di KJA Danau Sipin adalah dengan teknis pemanfaatan tanaman air sebagai fitoremediasi. Oleh karena itu, studi mengenai pemanfaatan tanaman air azolla sebagai fitoremediasi kandungan merkuri (hg) pada air dan daging ikan patin $P$. hypopthalmus di KJA Danau Sipin Jambi sangat diperlukan. Penelitian ini diharapkan dapat memberikan informasi tentang keuntungan tanaman air untuk mengatasi dampak toksisitas merkuri yang terakumulasi pada air dan daging ikan di Perairan Danau Sipin Jambi pada ikan patin P. hypopthalmus.

\section{METODE PENELITIAN}

Penelitian ini dilaksanakan selama 4 bulan dari bulan Juni samapi September 2017. Tempat pelaksananan penelitian di Perairan Danau Sipin Jambi. Metode penelitian yang digunakan adalah ekperimen demplot tanaman azolla dengan desain rancangan acak lengkap (RAL) dengan 4 (empat) perlakuan yang diberi 3 (tiga) ulangan. RAL berbentuk perlakuan A. Padat tebar azolla 0,5 $\mathrm{Kg} / \mathrm{M}^{2}$, B. Padat tebar azolla $1,0 \mathrm{Kg} / \mathrm{M}^{2}$, C. Padat tebar azolla $1,5 \mathrm{Kg} / \mathrm{M}^{2}$, dan D. Padat tebar azolla $2,0 \mathrm{Kg} / \mathrm{M}^{2}$. Analisis kandungan $\mathrm{Hg}$ pada Air, ikan diukur dengan menggunakan spektrofotometer serapan atom (Atomic Absorption Spectrophotometer) (SNI 6989.6:2009) .

Desain wadah penelitian yang digunakan adalah dengan memodifikasi KJA yang ada di lokasi penelitian yaitu dengan meletakkan tanaman Azolla pada setiap sisi KJA. Wadah untuk penempatan Azolla berukuran 0,5 x 3 meter dengan menggunakan kerangka kayu dan jaring hapa dengan ukuran mata jaring $1 \mathrm{~mm}$. Desain wadah penelitian disajikan pada Gambar 1 yaitu sebagai berikut;

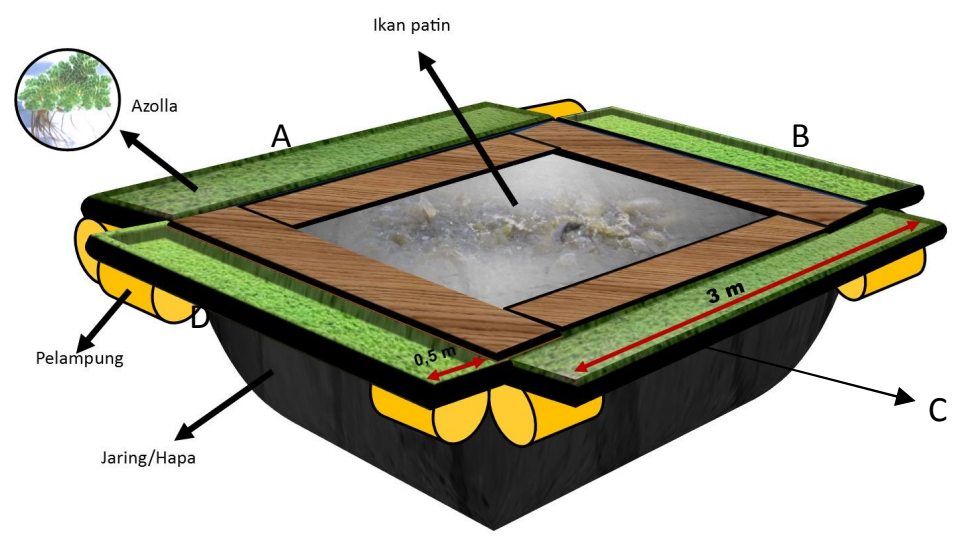

Gambar 1. Desain wadah penelitian pemanfaatan Azolla sebagai fitoremediasi kandungan $\mathrm{Hg}$ pada KJA di danau sipin propinsi Jambi

Metode pengambilan sampel yang digunakan adalah non probability sampling atau pengambilan sampel tanpa peluang (Wibisono 2003 dalam Rosiah, 2005). Sampel diambil menggunakan metode purposive sampling karena pertimbangan tertentu yang dipilih secara sengaja. Sebelum dilakukan pengambilan sampel terlebih dahulu dilakukan tahapan persiapan, antara lain botol sampel disiapkan dan di beri label sesuai perlakuan, botol sampel daging disiapkan dan di label sesuai posisi pengambilan, cool box merupakan wadah 
Jurnal Akuakultur Sungai dan Danau Vol. 3 No. 1 Tahun 2018 Hal. 27 - 34

yang digunakan sebagai tempat botol sampel air dan sampel daging ikan patin. Pengambilan sampel air dan daging ikan dilakukan setiap 10 hari selama periode penelitian. Pengambilan sampel daging ikan dilakukan terhadap ikan patin yang berada di dalam KJA yang merupakan wadah penelitian yang diberi perlakuan. Ikan tersebut dibedah dengan alat bedah dan diambil bagian daging pada punggung atas ikan. Daging tersebut disimpan di dalam botol sampel yang sudah disediakan. Sampel air diambil dengan menggunakan botol sampel berukuran $250 \mathrm{ml}$ yang sudah ditetesi larutan asam nitrat sebanyak tiga tetes sesuai teknis prevarasi sampel, sampel air di label sesuai dengan tiitk pengambilan dan disimpan di dalam cool box untuk siap di analisis.

Parameter-parameter yang diamati pada penelitian ini adalah Bioakumulasi Kandungan $\mathrm{Hg}$ di Air dan Daging Ikan. Prinsip analisisnya berdasarkan Hukum Lambert-Beert yaitu banyaknya sinar yang diserap berbanding lurus dengan kadar zat. Persamaan garis antara konsentrasi logam dengan absorbansi adalah persamaan linier dengan koefisien arah positif: $\mathrm{Y}=\mathrm{a}+$ bX. Cara kerjanya yaitu berdasarkan atas penguapan larutan sampel yang kemudian logam terkandung didalamnya diubah menjadi atom bebas. Atom tersebut mengabsorpsi radiasi dari sumber cahaya dari lampu katoda (Hollow Cathode Lamp) yang mengandung unsur target. Banyaknya penyerapan radiasi kemudian diukur pada panjang gelombang tertentu menurut jenis logamnya. Pada ikan, kandungan $\mathrm{Hg}$ diuji hanya pada bagian daging. Sebelum dianalisis dengan Atomic Absorption Spectrophotometer (AAS), tiap sampel organ mengalami proses destruksi hingga menjadi larutan sampel.

Data yang diperoleh ditabulasi dan dianalisis menggunakan program Microsoft Excel 2007 dan SPSS 18.0, yang meliputi Analisis Ragam dengan uji F pada selang kepercayaan 95\%, untuk menentukan ada atau tidaknya pengaruh perlakuan terhadap total konsentrasi $\mathrm{Hg}$ pada ikan. Apabila berpengaruh nyata, untuk melihat perbedaan antar perlakuan, diuji lanjut menggunakan uji Duncan.

\section{Kandungan Merkuri Dalam Air}

\section{HASIL DAN PEMBAHASAN}

Selama berlangsungnya kegiatan penelitian diperoleh data kandungan $\mathrm{Hg}$ didalam air yang diambil pada wadah perlakuan disajikan dalam bentuk grafik pada Gambar 2.

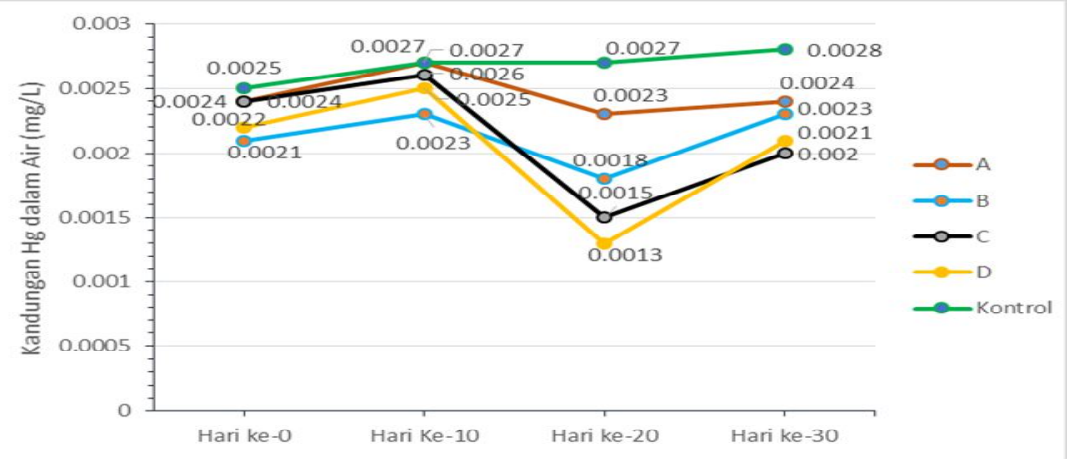

Gambar 2. Rata-rata nilai kandungan merkuri $(\mathrm{Hg})$ dalam air pada setiap unit perlakuan 
Jurnal Akuakultur Sungai dan Danau Vol. 3 No. 1 Tahun 2018 Hal. 27 - 34

Hasil analisis sidik ragam dan Grafik pada Gambar 2 menunjukkan bahwa perbedaan kepadatan azolla yang ditebar disekitar unit KJA memberikan perbedaan yang signifikan terhadap kandungan merkuri didalam air terutama pada hari ke 20, sedangkan pada hari ke-0, hari ke-10, dan hari ke-30 tidak menunjukkan perbedaan yang signifikan.

Pada hari ke 10 kandungan $\mathrm{Hg}$ didalam air cenderung meningkat, hal tersebut terjadi karena adanya proses interaksi bakteri rizoferik pada akar untuk merubah merkuri dari bentuk yang tidak dapat diserap (anorganik) menjadi unsur yang dapat diserap (organik). Selama berlangsungnya proses tersebut merukuri didalam air belum dapat diserap oleh akar tanaman azolla sehingga kandungan $\mathrm{Hg}$ didalam air cenderung meningkat. Kemampuan tanaman azolla dalam menyerap merkuri mulai terlihat pada hari ke-20. Semakin banyak tanaman azolla yang berada disekitar KJA berdampak terhadap semakin menurunya kandungan $\mathrm{Hg}$ didalam air.

Proses pertama tumbuhan hiperakumulator dalam merubah logam adalah interaksi rizosferik pada zona perakaran, dimana terjadi proses pengolahan unsurunsur di dalam tanah dari bentuk yang tidak dapat diserap menjadi bentuk yang dapat diserap dengan melibatkan sejumlah eksudat yang diproduksi akar (Salt, 2006).

\section{Kandungan Merkuri (Hg) Dalam Daging Ikan}

Adanya kandungan merkuri didalam perairan sangat berpeluang terjadinya akumulasi didalam tubuh ikan. Hasil pengamatan dan analisa laboratorium terhadap kandungan $\mathrm{Hg}$ yang terakumulasi didalam daging ikan patin siam yang dipelihara selama 30 hari diperoleh data yang disajikan dalam bentuk grafik pada Gambar 3.

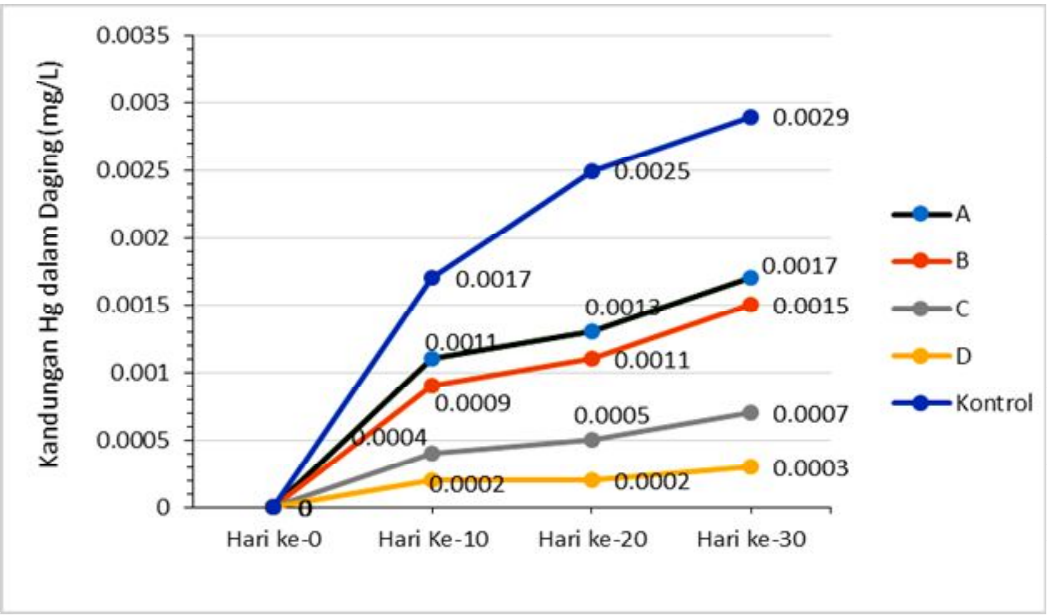

Gambar 3. Rata-rata nilai kandungan merkuri $(\mathrm{Hg})$ dalam daging ikan patin siam pada setiap unit perlakuan

Berdasarkan hasil analisis sidik ragam dan grafik pada Gambar 3 menunjukkan bahwa padat tebar azolla memberikan pengaruh yang tidak signifikan tehadap kandungan merkuri didalam daging ikan patin siam. Namun demikian semua perlakuan menunjukkan nilai kandungan merkuri yang lebih rendah dari kontrol. Artinya tumbuhan azolla mampu menekan tingkat akumulasi 
Jurnal Akuakultur Sungai dan Danau Vol. 3 No. 1 Tahun 2018 Hal. 27 - 34

merkuri didalam tubuh ikan. Hal tersebut terkait dengan kemampuan azolla menyerap merkuri yang terkandung didalam air, sehingga kandungan merkuri terlarut akan turun, selanjutnya tingkat akumulasi pada tubuh ikan dapat ditekan.

Terakumulasinya merkuri kedalam tubuh ikan terjadi secara langsung melalui proses metabolisme, osmoregulasi, dan secara tidak langsung yaitu melalui rantai makanan. Jalur masuknya $\mathrm{Hg}$ ke dalam tubuh ikan diawali ketika terjadinya proses perombakan ion merkuri anorganik menjadi organik yang dilakukan oleh bakteri aerob dalam bentuk ion metil merkuri. Merkuri yang bersifat organik tersebut akan dimanfaatkan oleh plankton, dan rantai berikutnya plankton akan dimakan oleh ikan.

Menurut Syahrizal dan Arifin (2016), Oleh bakteri aerob, ion merkuri akan diendapkan dalam bentuk metil merkuri dan kemudian diuraikan menjadi ion metil merkuri dan di dalam air akan mudah diambil oleh plankton yang konsentrasinya akan menjadi berlipat ganda. Oleh bakteri yang aerob, ion merkuri lansung ditransfer menjadi metil atau etil merkuri dan menjadi bagian dari tubuh bakteri. Sehingga bakteri akan dimangsa oleh mikroorganisme lain yang ada di air seperti plankton, dan selanjutnya plankton akan dimangsa oleh ikan.

\section{KESIMPULAN DAN SARAN}

Kepadatan azolla memberikan pengaruh berbeda tidak nyata tehadap kandungan merkuri $(\mathrm{Hg})$ didalam air dan daging ikan. Namun demikian semua perlakuan menunjukkan nilai kandungan merkuri yang lebih rendah dari kontrol. Artinya tumbuhan azolla mampu menekan tingkat akumulasi merkuri di air dan didalam tubuh ikan. Terkait dengan adanya akumulasi merkuri didalam daging ikan patin siam, disarankan untuk melakukan penelitian lanjutan tentang jarak yang efektif antara letak tanaman ozolla dengan unit budidaya ikan.

\section{DAFTAR PUSTAKA}

Anonim.1997.Fateand transport of Mercury in the Environment, Mercury Study Reportto Congress Volume III, EPA-452/R 97005,U.S. Environmental Protection Agency, Office of Air Quality Planning \& Standarts and Office of Reseachand Development.

Anonim,2001,Peraturan Pemerintah Republik Indonesia Nomor 82 Tahun 2001 Tentang Pengelolaan Kualitas Air dan Pengendalian Pencemaran Air, www.ri.go.id/produk_uu/isi/pp2001/pp82'01.htm

Blanchard, J. 2009. Copper toxicity and accumulation: physiology, chemistry and molecular biology [desertasi]. Miami (US): University of Miami.

Browman, M W, D. L. Kramer. 1985. Pangasius Sutchi (Pangasiidae), An AirBreathing Catfish That Uses The

Carvalho, C.S, MN Fernandes. 2006. Effect of temperature on copper toxicity and haematological responses in the Neotropical fish, Prochilodus scrofa at low and high pH. Aquaculture. 251:109-117.

Gabbrielli R, Mattioni C, Vergnano O. (1991). Accumulation mechanisms and heavy metal tolerance of a nickel hyperaccumulator. J Plant Nutr 14:10671080

Geyer, H.J, G.G, Rimkus, I, Scheunert, A, Kaune, Schramm, A, Kettrup, M, Zeeman, CG, Derek, Muir, Hansen, Mackay. 2000. Bioaccumulation and 
Jurnal Akuakultur Sungai dan Danau Vol. 3 No. 1 Tahun 2018 Hal. 27 - 34

ISSN Print 2503-4766

ISSN Online 2597-8837

Occurrence of Endocrine-Disrupting Chemicals (EDCs), Persistent Organic Pollutants (POPs), and Other Organic Compounds in Fish and Other Organisms Including Humans. Handbook of Environmental Chemistry Vol.2 Part J Bioaccumulation.

Handajani, H. 2011 Optimalisasi Substitusi Tepung Azolla Terfermentasi Pada Pakan Ikan Untuk Meningkatkan Produktivitas Ikan Nila Gift. Jurnal Teknik Industri, Vol. 12, No. 2, Agustus 2011: 177-181

Hardjamulia, A. 1976. Problems in freshwater fish breeding and the results of the introduction of improved techniques in Indonesia. Research Institute for Inland Fisheries. Sukabumi. 12 pp.

Haqim, L. Riyanto, Prayitno, 2013. Analisis Kandungan Merkuri (Hg) Pada Air Dan Ikan Nilem (Osteochilus Hasseltii) (Studi Kasus Di Perairan Sungai Kaligarang Semarang). Jurnal LOGIKA, Maret 2003 Vol. 9, No. 10

Husna, N. 2013. Budidaya Azolla. http://jejakpenyuluh. blogspot.co.id/2013/08/ budidaya - azolla.html

[KKP] Kementrian Kelautan dan Perikanan. 2014. Statistik perikanan budidaya kolam [Internet]. [diunduh 10 Februari 2015]. Tersedia pada http://sidatik.kkp.go.id.

Lasut, MT. 2009. Proses Bioakumulasi dan Biotransfer Merkuri (Hg) pada Organisme Perairan di dalam Wadah Terkontrol. Jurnal Matematika Dan Sains, September 2009, Vol. 14 No. 3.

Legendre M, J, Slembrouck, J, Subagja. 1998. First Results on growth and artifial propagation of Pangasius djambal in Indonesia. In the biological Diversity and Aquaculture of Clariid and Pangasiid Catfishes In South East Asia. Proceeding Of The Midtem Workshop Of The "Catfish Asia Project". 11-15 May, 1998. Cantho. Vietnam. P. 97-101.

LRPTBPAT. 2006. Dokumen Usulan Pelepasan Patin Hibrida. Loka Riset Pemuliaan dan Teknologi Budidaya Perikanan Air Tawar. Loka Riset Pemuliaan dan Teknologi Budidaya Perikanan Air Tawar (LRPTBPAT). Sukamandi. 14 hal.

Mangkoedihardjo, S. 1999. Ekotoksikologi Keteknikan. Jurusan Teknik Lingkungan, ITS, Surabaya

Nagahama, Y. 1983. The Functional Morphology Of Teleost Gonad. P. 223 - 275. In WS Hoar, DJ Randall, and

Pouyaud, L. R. Gustiano, M. Legendre. 1998. Phylogenetic relationship among pangasiid catfish species (Siluriformes, Pangasiidae) and new insights on their zoogeography. In: M. Legendre and A. Parisele (eds.). The Biological Diversity and Aquaculture of Clariid and Pangasiid Catfishes in South-East Asia. Proceeding of The Mid-Term Workshop of the Catfish Asia Project, 11-15 May 1998. Cantho, Vietnam. Pp. 49-56

Pouyaud, L, R. Gustiano, G.G, Teugels. 2004. Contribution to the phylogeny of the Pangasiidae based on mitochondrial $12 \mathrm{~S}$ rDNA. Indonesian Journal of Agricultural Science 5(2): 45-62

Prihatman, K. 2000. Budidaya Ikan Patin (Pangasius pangasius) : Proyek Pengembangan Ekonomi Masyarakat Pedesaan

Roberts, T.R, C. Vidthayanon. 1991. Systematic revision of the Asian catfish family Pangasiidae, with biological observations and description of three 
Jurnal Akuakultur Sungai dan Danau Vol. 3 No. 1 Tahun 2018 Hal. 27 - 34

new species. Proceedings of the Academy of Natural Sciences of Philadelphia 143: 97-144.

Saanin, H. 1968. Taksonomi dan Kunci Identifikasi Ikan. Binacipta : Bandung

Salt DE. (2000). Phytoextraction: Present applications and future promise. Di dalam: Wise DL, Trantolo DJ, Cichon EJ., Inyang HI, dan Stottmeister U (Ed). Bioremediation of Cotaminated Soils Marcek Dekker Inc. New York; Basel. hlm 729-743

Salt DE. 2006. An Extreme Plant Lifestyle: Metal Hyperaccumulation. Plant Physiology. Fourth Edition by Taiz L \& E Zeiger. Chapter 26. Sinauer Assoc.Inc.

Setiawan, A.A, Eddy, S. 2011. Kandungan $\mathrm{Pb}$ pada Berbagai Jenis Ikan di Perairan Sungai Musi Palembang Jurnal Mandiri Agritek, kopertis Wilayah II.

Suseno H, Hudiyono, Budiawan, D.S Wisnubroto. 2010. Bioakumulasi Merkuria Anorganik Dan Metil Merkuri Oleh Oreochromis Mossambicus: Pengaruh Konsentrasi Merkuri Anorganik Dan Metil Merkuri Dalam Air. Jurnal Teknologi Pengelolaan Limbah (Journal of Waste Management Technology), Volume 13 Nomor 1.

Syahrizal, Arifin. Y. 2016. Analisis Kandungan Merkuri (Hg) Pada Air Dan Daging Ikan Patin Siam (Pangasius Hypopthalmus) Di Kja Danau Sipin Jambi. Jurnal Akuakultur Sungai dan Danau. Program Studi Budidaya Perairan Fakultas Pertanian Universitas Batanghari Jambi.

Yang, J X, X.Y Chen, Y. R Chen. 2007. On the population status of Pangasiid catfishes in Lancangjiang River Basin, China. Zoological Research 28(1): 63-67. (in Chinese with English abstract). 